Military Technical College

Kobry El-Kobba,

Cairo, Egypt

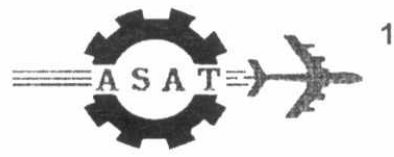

11-th International Conference

on Aerospace Sciences \&

Aviation Technology

\title{
EXPERIMENTAL INVESTIGATION ON THE INFLUENCE OF MUZZLE BRAKE GEOMETRY ON AUTOMATIC SMALL ARMS PERFORMANCE
}

\author{
Moghazy, M. A. *
}

\begin{abstract}
Fully automatic weapons have a short history, yet their inspection and methods of improving performance and accuracy of fire have been largely limited. Most of weapon performance parameters depend directly on the design of muzzle brake. The object of this work is to provide automatic small arms with a muzzle brake of a suitable design that would reduce its recoil velocity. This will reflect on the enhancement of the weapon performance.

A number of muzzle brakes of different configurations have been manufactured and tested. The target was to predict the muzzle brake efficiency, and the fire accuracy. The test device permits the evaluation of the recoil of small calibre rifle by measuring the maximum number of recoil parameters at the same time. Measurements included the time variation of recoil force and accelerations for mechanical vibrations (horizontal and vertical) for an automatic rifle $7.62 \times 39-\mathrm{mm}$, without and with muzzle brake. Furthermore, the projectile muzzle velocities, accuracy of fire and dispersion have been measured.

It was found experimentally that the recoil velocity of the rifle could be reduced by about $35 \%$. Improvement of dispersion and accuracy of fire could be reached through the suitable design for muzzle brake. This work may contribute to solving problems in design and selection of muzzle brake geometry in automatic small arms with different calibres to enhance the weapon performance.
\end{abstract}

\section{KEY WORDS}

Discharge gases, barrel muzzle, automatic small arms, muzzle brake performance.

\footnotetext{
- Egyptian Armed Forces
} 


\section{INTRODUCTION}

There is a great deal of interest in decreasing the recoil energy of guns and automatic small arms by providing the barrel with suitable muzzle brakes.

Dispersion, inaccuracy of fire and bad results in terminal ballistics represent major disadvantages. In guns and howitzers, such disadvantages could be overcome by increasing the destructive effect of shells and/or by correction of fire, especially in indirect firing [1]. However, in small arms, bad accuracy of fire is not admitted, where the targets are relatively small in size (personnel, light vehicles, ...etc.).

The designer of automatic small arms may face a great problem when it is required to design a suitable muzzle brake that would reduce the recoil energy while, in the same time, keeping the weapon accuracy of fire [2-4]. What makes the problem more difficult is the lack of published references that describes models for recoiling of automatic small arms. In particular, design of muzzle brakes of complex geometry for automatic small arms is not treated in the open literature[7-10].

In the present work, various muzzle brakes have been manufactured, studied and tested, through a systematic program to obtain the configuration that meets the best weapon performance. In fact, muzzle brake efficiency has a direct impact on the weapon performance. The forces transmitted to the firer a re reduced, which yields better accuracy and higher firing rate.

\section{EXPERIMENTAL WORK \& DISCUSSION}

The experimental work was carried out in the ballistic shooting range, where the test rig includes automatic rifle $7.62 \times 39(\mathrm{~mm})$ connected with force transducer which has been used for measuring the weapon recoil force. The system allows computing both the recoil impulse and recoil velocity of automatic rifle. Two accelerometer transducers are attached to barrel muzzle in vertical and horizontal directions to pick up any barrel vibrations. Three groups of muzzle brake configurations with the same volume and the same total area of the side orifices were manufactured. The side orifices were made with different shapes. A scheme of the setup which includes: automatic rifle with its mountings, transducers fixed at the measuring locations, and instrumentations in the shooting range is shown in Fig. 1. Photographs of the different manufactured muzzle brakes are shown in Fig. 2. Detailed specifications of the muzzle brakes are listed in Table 1. A drawing of a muzzle brake which presented a suitable geometry is shown in Fig. 3.

In all the tests, the ammunition used were charged with $1.8 \mathrm{~g}$ of propellant mass in the cartridge cases, and the same automatic rifle $7.62 \times 39 \mathrm{~mm}$ was used.

The photographs in Figs. 4-5 show the automatic rifle with instruments for the experimental evaluation. Automatic rifle equipped with one of the experimental muzzle brakes is given in Fig.4, while the same rifle presented in Fig.5 is not equipped with a muzzle brake. 
Table 1. Specifications of manufactured muzzle brakes

\begin{tabular}{|c|c|c|c|c|c|c|c|c|}
\hline Muzzle brake specifications & \multicolumn{3}{|c|}{$1^{\text {st }}$ group } & \multicolumn{2}{|c|}{$2^{\text {nd }}$ group } & \multicolumn{3}{|c|}{$3^{\text {rd }}$ group } \\
\hline No. of muzzle brakes in iteration & \multicolumn{3}{|c|}{3} & \multicolumn{2}{|c|}{2} & \multicolumn{3}{|c|}{3} \\
\hline No. of side orifices & 2 & 2 & 2 & 3 & 2 & \multicolumn{3}{|c|}{5 longitudinal } \\
\hline $\begin{array}{l}\text { Angles between side orifices and } \\
\text { barrel center line, } \psi\left[\left[^{\circ}\right]\right.\end{array}$ & 110 & 120 & 130 & 90 & 90 & \multicolumn{3}{|c|}{5 vents/ 72} \\
\hline Angle of flow of side orifices, $\varphi\left[^{\circ}\right]$ & \multicolumn{3}{|c|}{0} & \multicolumn{2}{|c|}{0} & 30 & 30 & 32 \\
\hline $\begin{array}{l}\text { Diameter of front opening of } \\
\text { muzzle brake [mm] }\end{array}$ & 9 & 9 & 9 & 9 & 10 & 8.5 & 8.3 & 8.2 \\
\hline $\begin{array}{l}\text { Internal volume of muzzle brake } \\
\text { chamber }\end{array}$ & \multicolumn{8}{|c|}{ The same volume } \\
\hline Total areas of side orifices & \multicolumn{8}{|c|}{ The same total areas of side orifices } \\
\hline
\end{tabular}

The setup enables to measure the following parameters in the same time:
a. Projectile muzzle velocity,
b. Recoil force,
c. Vertical acceleration at barrel muzzle,
d. Horizontal acceleration at barrel muzzle,
e. Dispersion \& accuracy of fire,
f. Rifle recoil velocity.

The main objective of experimental work is to enhance the weapon performance by reducing the forces that may act on the firer.

\section{a. Projectile Muzzle Velocity}

Projectile muzzle velocity was measured and recorded by using the "Oehler" Chronograph. The projectile crosses two screens, 3 meters apart, placed in the line of fire, close to the muzzle. The setup dedicated to evaluate the projectile muzzle velocity is a stand alone system, complete with processing and display units. The mean $v$ alue of the $m$ easured projectile muzzle v elocity of automatic $r$ ifle without and with muzzle brakes, after correction, is $720 \mathrm{~m} / \mathrm{s}$. [5]

\section{b. Recoil Force}

The recoil force generated by firing a rifle has two components: one is attributed to the momentum of the projectile and the other to that of the escaping gas. In the case under investigation, a higher proportion of the recoil will be generated by the expanding gas from the barrel [7-9]. Unfortunately, there is no simple ratio which will tell exactly what proportion of the recoil is generated by the escaping gas as opposed to the projectile. 
The recoil force is measured using a piezoelectric force transducer ( $B \& K$, type 8200) connected to an HP (Hewlett Packard) dynamic signal analyzer through to a conditioning amplifier (B\& K, type 2626) as shown in Figs. 4-5.

The measured recoil force - time history for automatic rifle without muzzle brake is shown in Fig. 6. Muzzle brake with side orifice inclination angle $\psi=110^{\circ}$ resulted in a decrease in recoil force of about $17 \%$. For inclination angles $\psi=120^{\circ}, 130^{\circ}$ the average reduction of the recoil force amounted to $25 \%$. The recoil force - time history of automatic rifle with muzzle brakes of the first group $\left(\psi=120^{\circ}, 130^{\circ}\right)$ is shown in Fig. 7. The reduction of the recoil force may be explained by the deflection of discharged gases.

The second group, which has muzzle brake with three side orifices is represented in Fig. 8. The reduction of recoil force is only $23 \%$, which is $2 \%$ less as compared to the first group. However, for front opening diameter of $10 \mathrm{~mm}$, the effect of muzzle b rake was a s l ow as $13 \%$. This m ay be linked to the fact that m ost of propellant gases are discharged from front opening after the projectile departure.

The lowest value for recoil force has been encountered in the third group of muzzle brakes. As could be seen from Fig. 3, they have five longitudinal side orifices, distributed radially at $72^{\circ}$ and the nozzle vents are $\varphi=30^{\circ}, \varphi=31^{\circ}$ and $\varphi=32^{\circ}$ consequently. Figure 9 shows that the maximum reduction in recoil force, $35 \%$ is realized by this configuration. It is also noticed that the effect of the number of side orifices on the shape of the recoil force-time curve is negligible relative to the effect inclination of side orifices.

\section{c. Vertical Acceleration at Barrel Muzzle}

Measurements of the vertical acceleration at barrel muzzle for the first group, Figs. 10,11 , showed $60 \%$ higher than the case of automatic rifle without muzzle brake. This may be explained by the sudden enlargement in muzzle brake chamber diameter, which causes rocking of projectile. Such higher values of vertical accelerations represent important sources of bad dispersion and accuracy of fire.

To avoid the defect in first group, the number of side orifices in the second group is increased to three. As seen in Fig. 12, the vertical acceleration is raised by only $23 \%$ as compared to the case without muzzle brake.

Seeking for a better performance, the number of side orifices is increased to five in the third muzzle brake group. Figure 13 shows that the maximum recorded vertical acceleration is higher than automatic rifle without muzzle brake by about $3 \%$. Such difference is practically negligible and it can be said that the vertical acceleration of at the barrel muzzle without brake could be maintained.

\section{d. Horizontal Acceleration at Barrel Muzzle}

The of results of measurement of the horizontal acceleration at the barrel muzzle are shown in Figs. 14 through17 and in Table 2. It should be noted that the major effect of the muzzle brake on the rifle vibrations is caused by the vertical 
acceleration. It is evident from the measurement results that horizontal acceleration has only minor effect on vibration of the at the barrel muzzle.

\section{e. Dispersion and Accuracy of Fire}

Effect of the muzzle brake on the rifle vibrations is reflecting on the vertical acceleration and the horizontal acceleration at the barrel muzzle, in particular, during periods of intermediate ballistics and external ballistics. It has also an influence on the aiming towards the target and the accuracy of hitting. Such effect has been investigated through the use of a special electronic target intended to determine the dispersion and a ccuracy of fire for the different groups of muzzle brakes. The best performance was obtained with the third group as indicated in Fig. 18.

\section{f. Recoil Velocity}

Recoil is the rearward motion of the rifle in reaction to the forward motion imparted to the projectile and propellant gases. The forward momentum gained by the projectile and gases is accompanied by an identical gain in rearward momentum of the rifle. The dynamic signal analyzer allows to trace the force-time history, and to get the recoil impulse. The recoil impulse, I, is defined by the following integral.

$$
\mathrm{I}=\int_{0}^{1} F \mathrm{dt}
$$

Recoil velocity of the rifle is then computed by aid of the obtained recoil impulse together with the momentum of recoiling parts. [4]

Comparison between the recoil velocity-time histories for the rifle without muzzle brake and that of the third group could be seen in Fig. 19. The obtained recoil velocities are $1.32 \mathrm{~m} / \mathrm{s}$ and $0.86 \mathrm{~m} / \mathrm{s}$ respectively. The reduction in the recoil velocity when using muzzle brake could reach about $35 \%$, as realized by the third group.

\section{ANALYSIS OF EXPERIMENTAL RESULTS}

In the light of the present work, useful recommendations can be made regarding the geometry of the muzzle brake to be fitted with small arms. In order to increase the efficiency of the muzzle brake and, in the same time, enhance the overall weapon performance, the following design considerations have to be accounted for:

1. The exit diameter of the front opening of muzzle brake should not exceed p rojectile diameter by no m ore than $10 \%$. L arger holes would disturb the bullet as it crosses the threshold and may badly affect the accuracy of fire.

2. The chosen total area of the side orifices in the muzzle brake should not exceed 7 to 8 times the area of the front opening. Larger areas are associated with higher noise and require more trials to successfully hit the target. 
Table 2. Measured Recoil Parameters

\begin{tabular}{|c|c|c|c|c|c|c|}
\hline \multicolumn{3}{|c|}{ PARAMETER } & $\begin{array}{l}\text { Recoil Force } \\
\text { (N) }\end{array}$ & $\begin{array}{c}\text { Vertical } \\
\text { Acceleration } \\
\left(\mathrm{m} / \mathrm{s}^{2}\right)\end{array}$ & $\begin{array}{c}\text { Horizontal } \\
\text { Acceleration } \\
\left(\mathrm{m} / \mathrm{s}^{2}\right)\end{array}$ & $\begin{array}{c}\text { Projectile } \\
\text { muzzle } \\
\text { Velocity }(\mathrm{m} / \mathrm{s})\end{array}$ \\
\hline \multicolumn{3}{|c|}{ Without Muzzle Brake } & 1020.3 & 61.5 & 13 & 717 \\
\hline \multirow{3}{*}{$\begin{array}{l}\frac{0}{\pi} \\
\frac{\pi}{\pi} \\
\frac{\pi}{0}\end{array}$} & \multirow{3}{*}{$\begin{array}{c}1^{\text {st }} \\
\text { Group }\end{array}$} & $\psi=110^{\circ}$ & $\begin{array}{c}849 \\
\text { (Rejected) }\end{array}$ & $\begin{array}{c}87.64 \\
\text { (Rejected) }\end{array}$ & $\begin{array}{c}68 \\
\text { (Rejected) }\end{array}$ & 715 \\
\hline & & $\psi=120^{\circ}$ & 767.737 & 99.41 & 57.3 & 718 \\
\hline & & $\psi=130^{\circ}$ & 766 & 99 & 57 & 719 \\
\hline \multirow{5}{*}{ 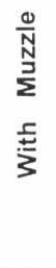 } & \multirow[t]{2}{*}{$\begin{array}{l}2^{\text {nd }} \\
\text { Group }\end{array}$} & $\psi=90^{\circ}$ & $\begin{array}{c}983 \\
\text { (Rejected) }\end{array}$ & $\begin{array}{c}98.675 \\
\text { (Rejected) }\end{array}$ & $\begin{array}{c}55.7 \\
\text { (Rejected) }\end{array}$ & 710 \\
\hline & & $\psi=90^{\circ}$ & 779.9 & 75.71 & 30.5 & 720 \\
\hline & \multirow{3}{*}{$\begin{array}{l}3^{\text {rd }} \\
\text { Group }\end{array}$} & $\varphi=30^{\circ}$ & 670.8 & 65.938 & 18.25 & 719 \\
\hline & & $\varphi=31^{\circ}$ & 667.737 & 64.511 & 17.3 & 721 \\
\hline & & $\varphi=32^{\circ}$ & 665 & 63.623 & 16.5 & 720 \\
\hline
\end{tabular}

3. Longitudinal side orifices have cooling effect on the discharged gases, so that they act as a flash damper. Consequently, the firer would not be easily discovered by hostile forces.

4. The choice of odd number of holes of longitudinal shape for muzzle brake orifices has eliminated the jump of the weapon, so increased accuracy of fire and decreased dispersion are realized.

A muzzle brake designed with suitable geometry could decrease recoil velocity by more than $35 \%$, taking into consideration the mentioned recommendations.

\section{CONCLUSIONS}

The suitable design of the muzzle brake could be obtained by comparing the weapon performance before and after equipping with muzzle brake.

With a properly installed muzzle brake, the recoil velocity would be reduced by about $40 \%$. Designing muzzle brakes should take into consideration various parameters of side orifices (area, shape, wall thickness, angles and numbers), together with the diameter of muzzle brake front opening and volume of muzzle brake chamber.

The present work explores and describes the suitable design a spects of muzzle brake for automatic small arms, aiming at attaining a good weapon performance The present analysis of the problem of recoil may help designing muzzle brake with reasonable efficiency. Still many other improvements can be made to increase the accuracy of fire of automatic small arms 


\section{REFERENCES}

[1] D. Boisson, R. Cayzac "Study of the Gas Discharge Occurring in a Gun Barrel after the Projectile Departure, $18^{\text {th }}$ International Symposium on Ballistics, San Antonio, TX, U. S. A., 15-19 November, 1999.

[2] Cekens E. and Plovie, "Recoil of small arms," $17^{\text {th }}$ International symposium on ballistics, VOL.2, 23-27, pp. 91-101, South Africa, March 1998.

[3] Hafez, F. A. "Internal Ballistics Measurements", Military Technical College, Printed Lectures, Cairo, 1971.

[4] Hafez, F. A. "Muzzle Brakes", Military Technical College, Printed Lectures, Cairo, 1970

[5] Hafez, F. A. "Internal Ballistics Measurements", Military Technical College, Printed Lectures, Cairo, 1971.

[6] Oswatitch, K., "Intermediate Ballistics," Institute fur theoretishe gasdynamik, Achen, Germany, June1964.

[7] Joglekar, A. M. and Phadke, M. S., "Iterative Modeling of Interior Ballistics of Small Arms", J. of Spacecraft VOL.19 NO. 7, July 1972, pp. 450-456.

[8] Patrick H., William E. Carscallen, "Compressible Fluid Flow", McGraw- Hill Book Company, New York, 1997.

[9] Cayzac, R., E. and Carette, Pr T. Alziary de Roquefort, "Intermediate Ballistics Computations and Validations," $17^{\text {th }}$ International Symposium on Ballistics, Midland, South Africa, 23-27 March 1998.

[10] Aboel-Khair, M. S., and Sherief, H. A. "Experimental Investigation of Recoil Force Automatic Small Arms and the Effect of Using Muzzle Brake", Mechanical Conference, M.T.C., Cairo, 2001. 


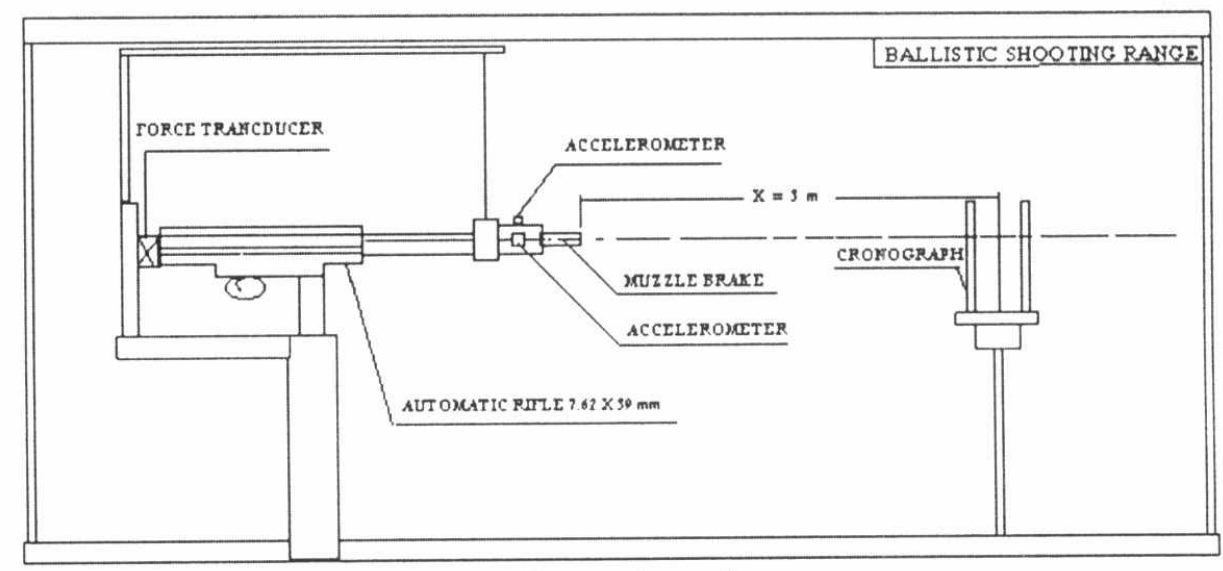

Fig. 1 Setup for experimental measurements.

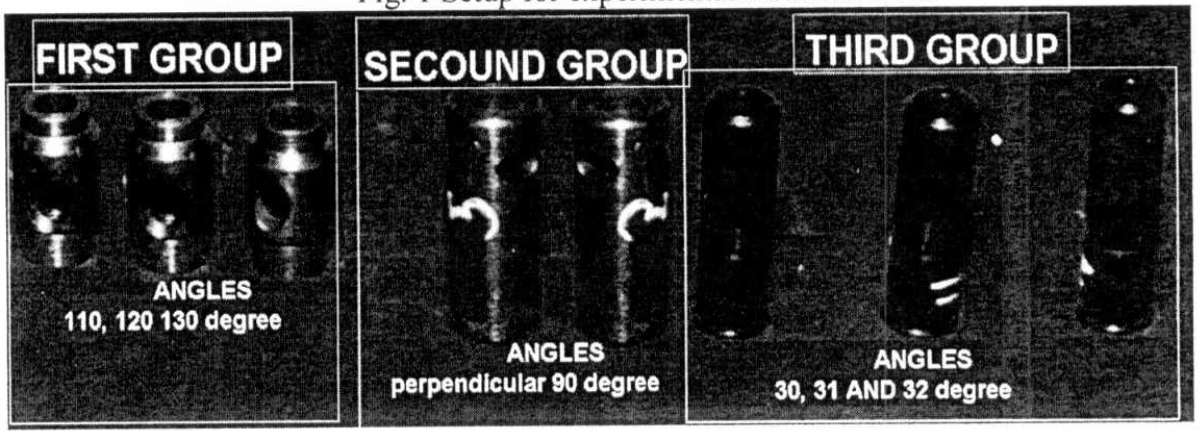

Fig. 2 Different manufactured muzzle brakes.

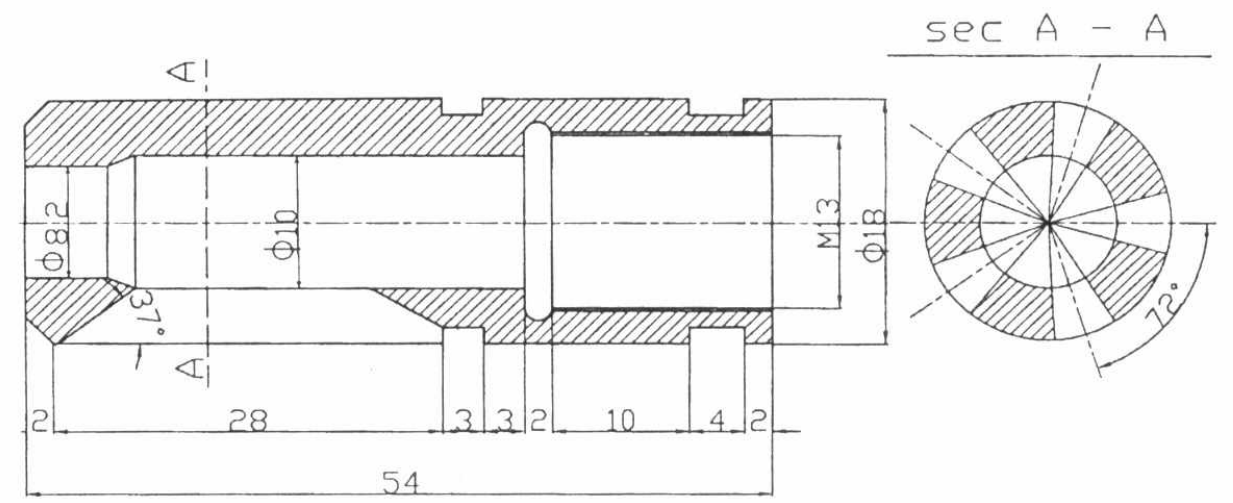

Fig. 3 Geometry of the suitable examined muzzle brake from the third group. 


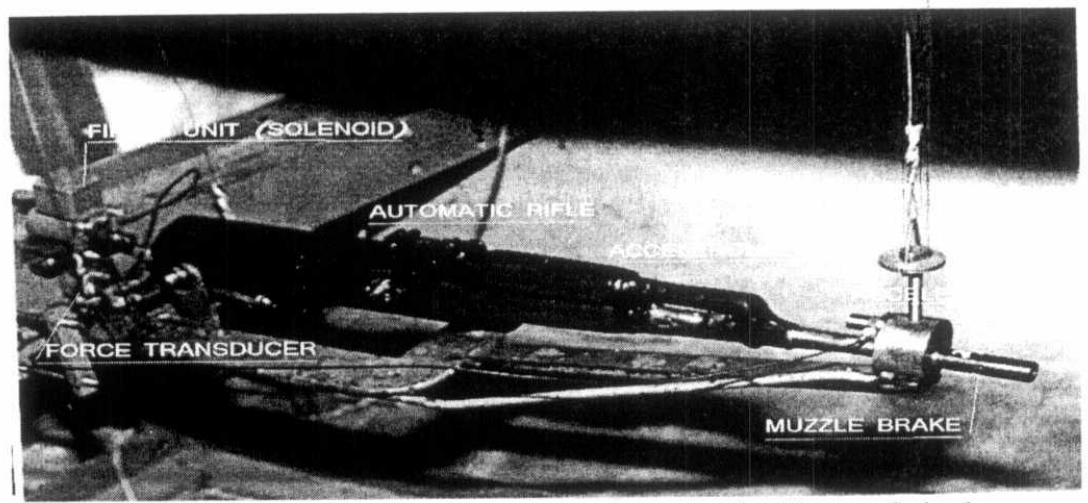

Fig. 4 Transducers for recoil parameters measured with muzzle brake.

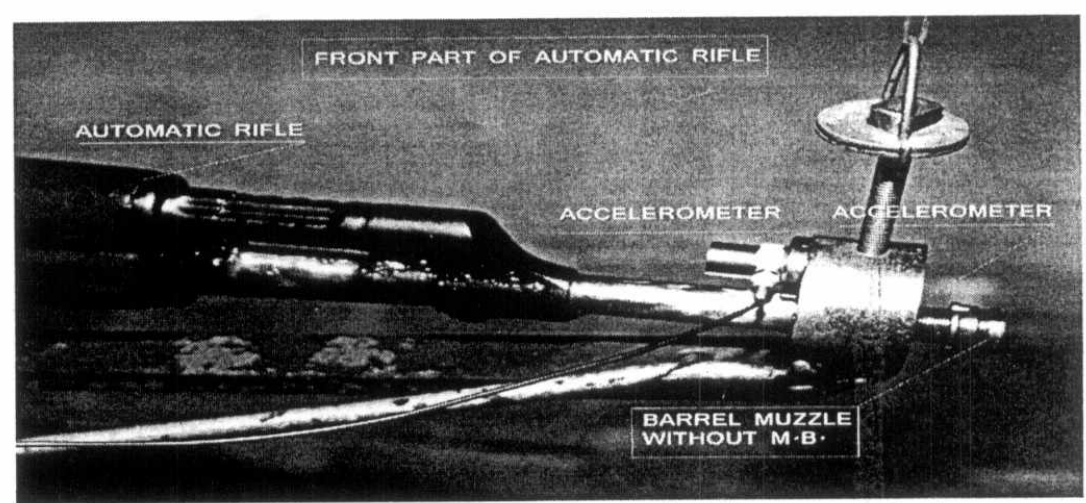

Fig.5 Transducers for recoil parameters measured without muzzle brake. $x=2.5391 \mathrm{~m}^{\mathrm{m}} \mathrm{S}=\mathrm{Se}$

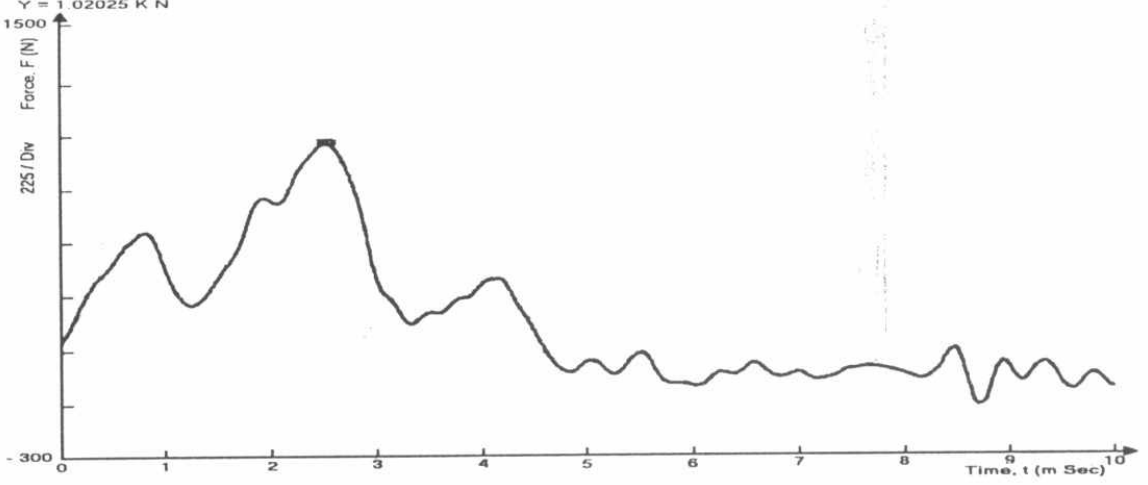

Fig. 6 Measured recoil force- time history for automatic rifle without muzzle brake. 


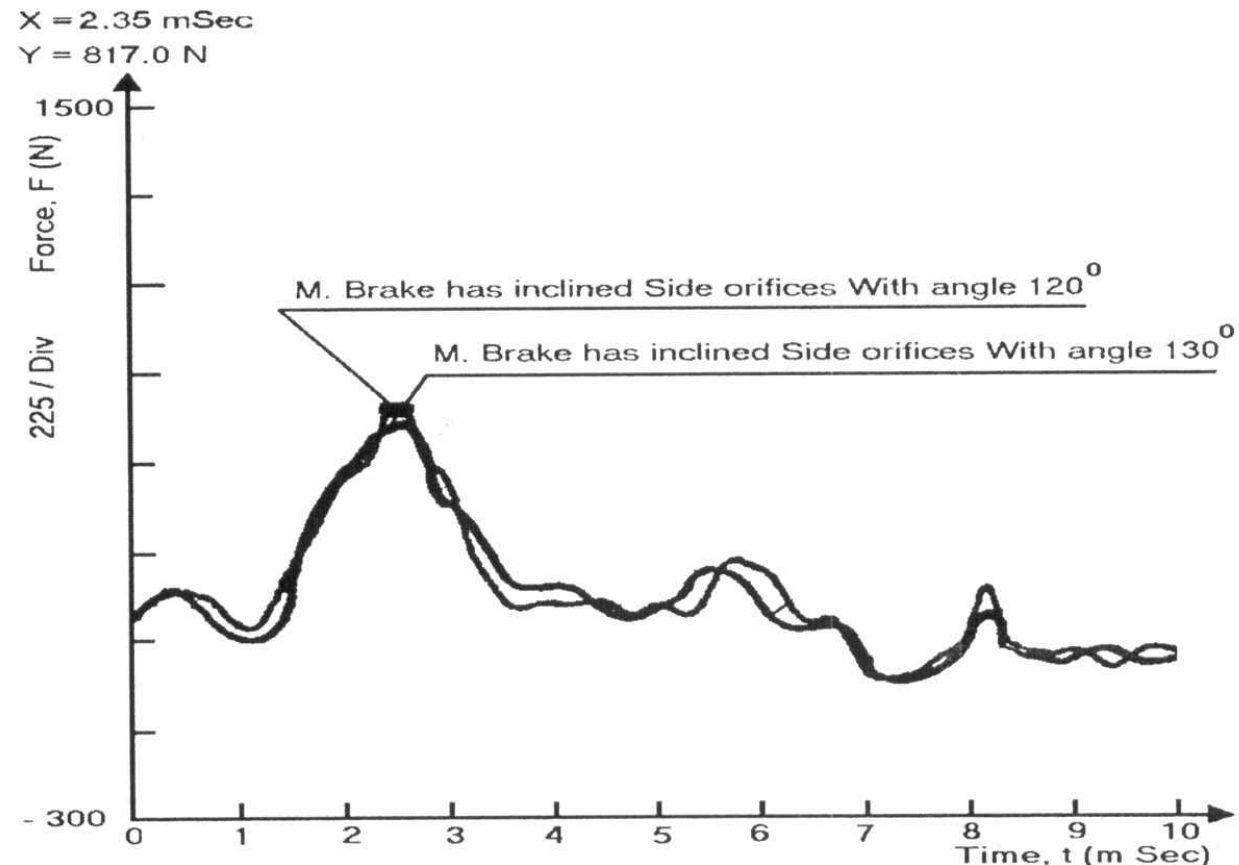

Fig. 7 Measured recoil force- time history for automatic rifle with muzzle brake for first group.

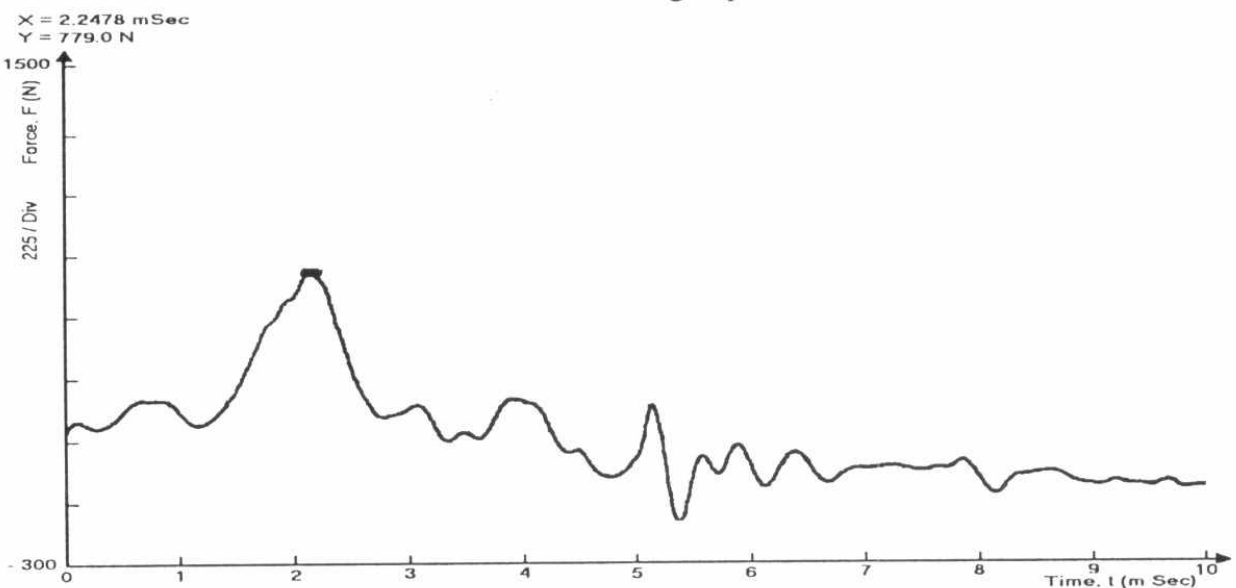

Fig. 8 Measured recoil force- time history for automatic rifle with muzzle brake for second group. 


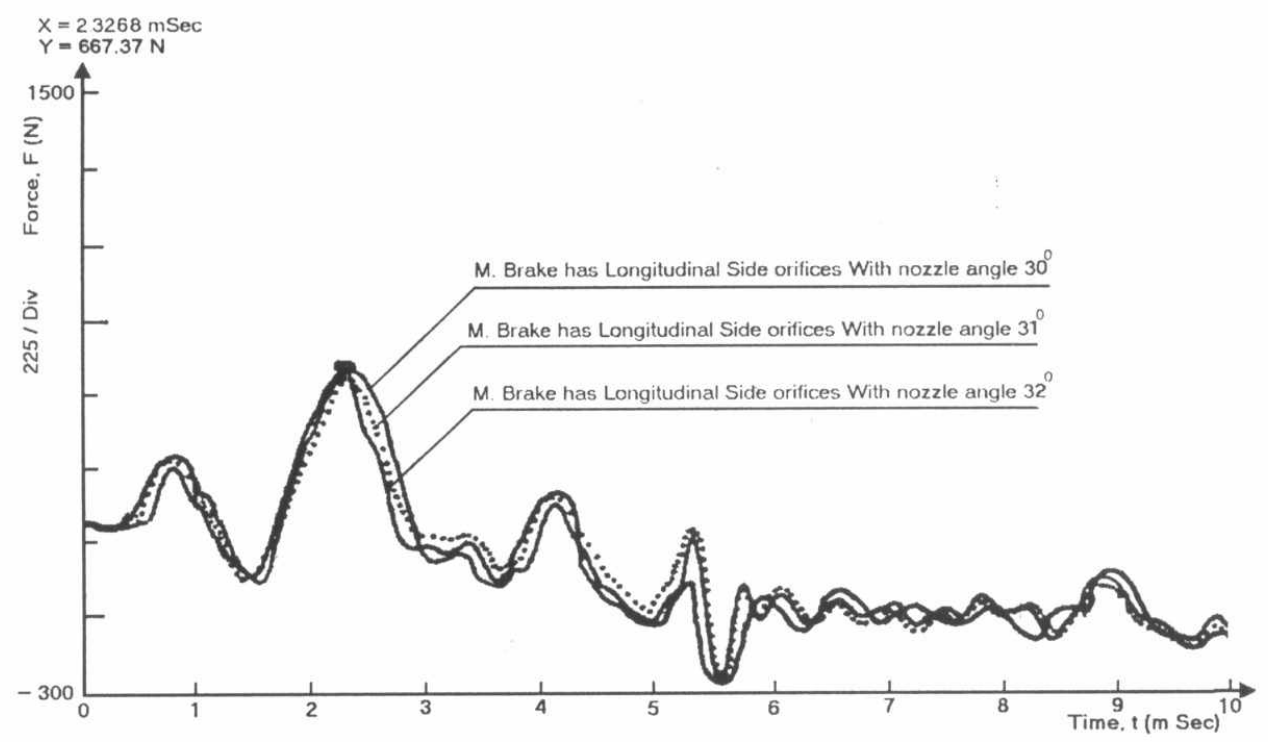

Fig. 9 Measured Recoil Force- time history for automatic rifle with muzzle brake for third group.

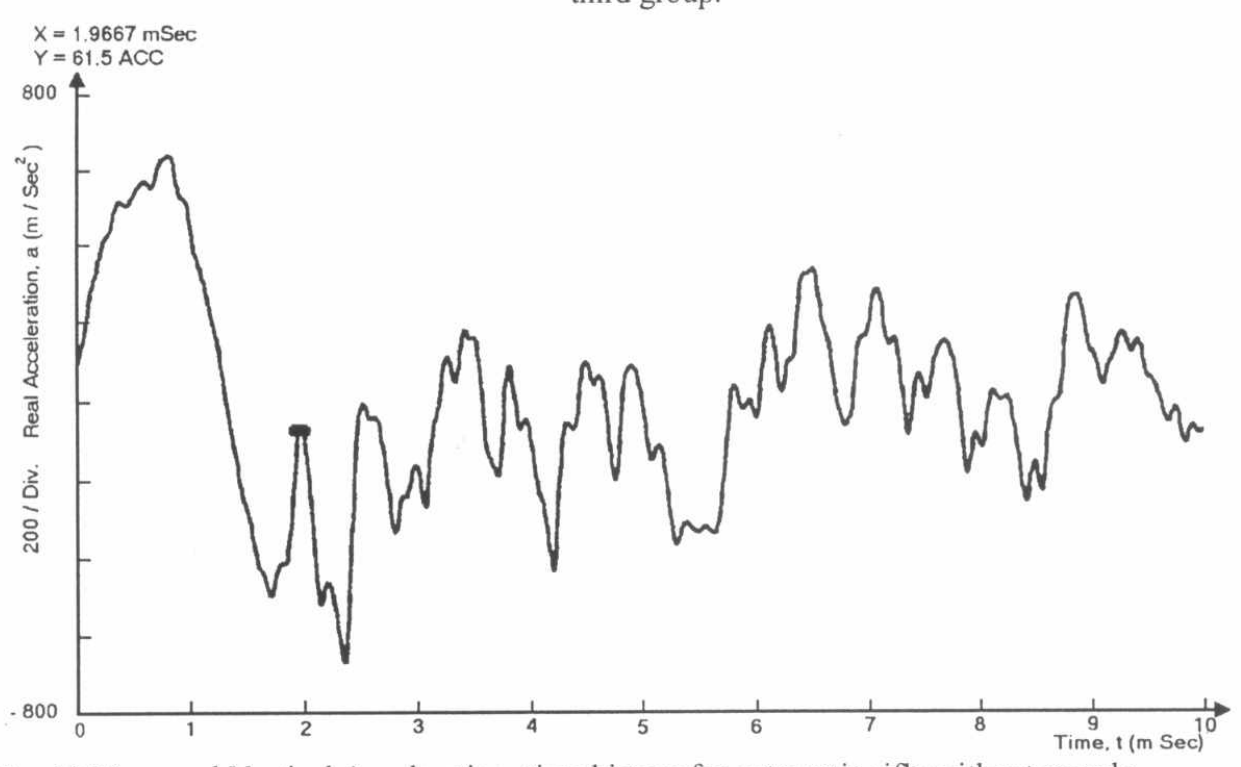

Fig. 10 Measured Vertical Acceleration- time history for automatic rifle without muzzle brake 


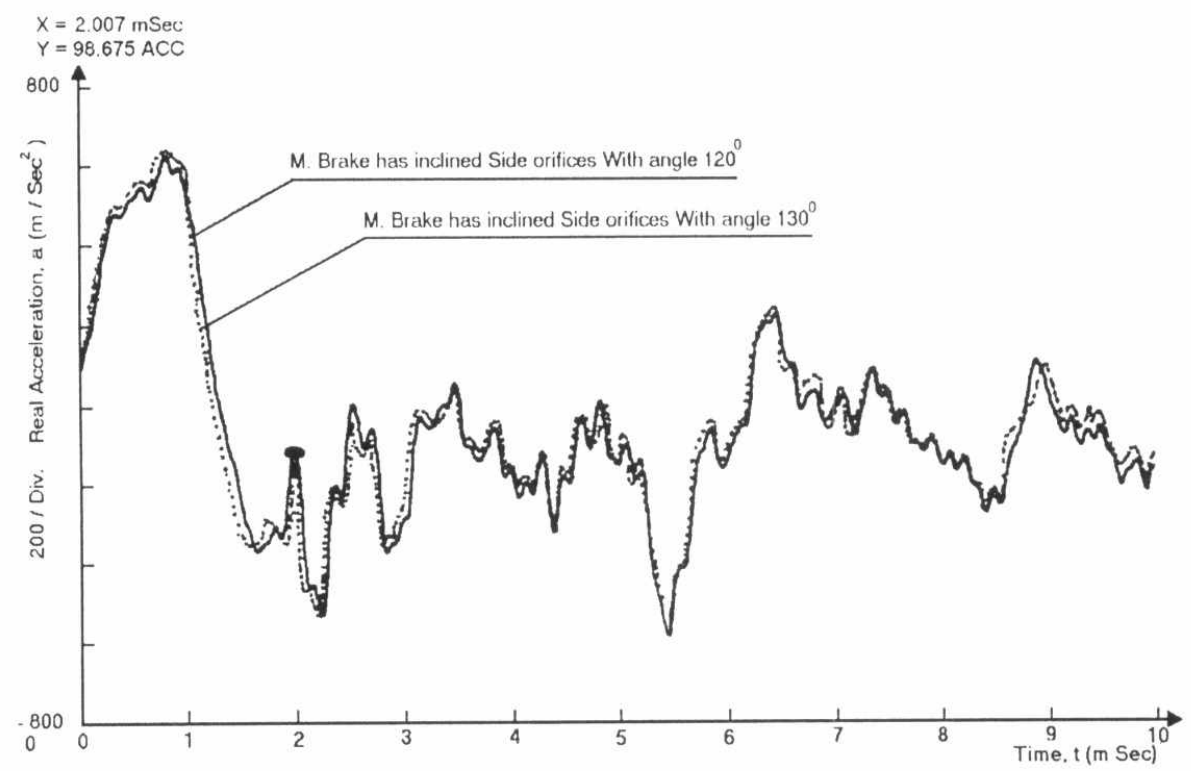

Fig. 11 Measured Vertical Acceleration-time history for automatic rifle with muzzle brake for first group.

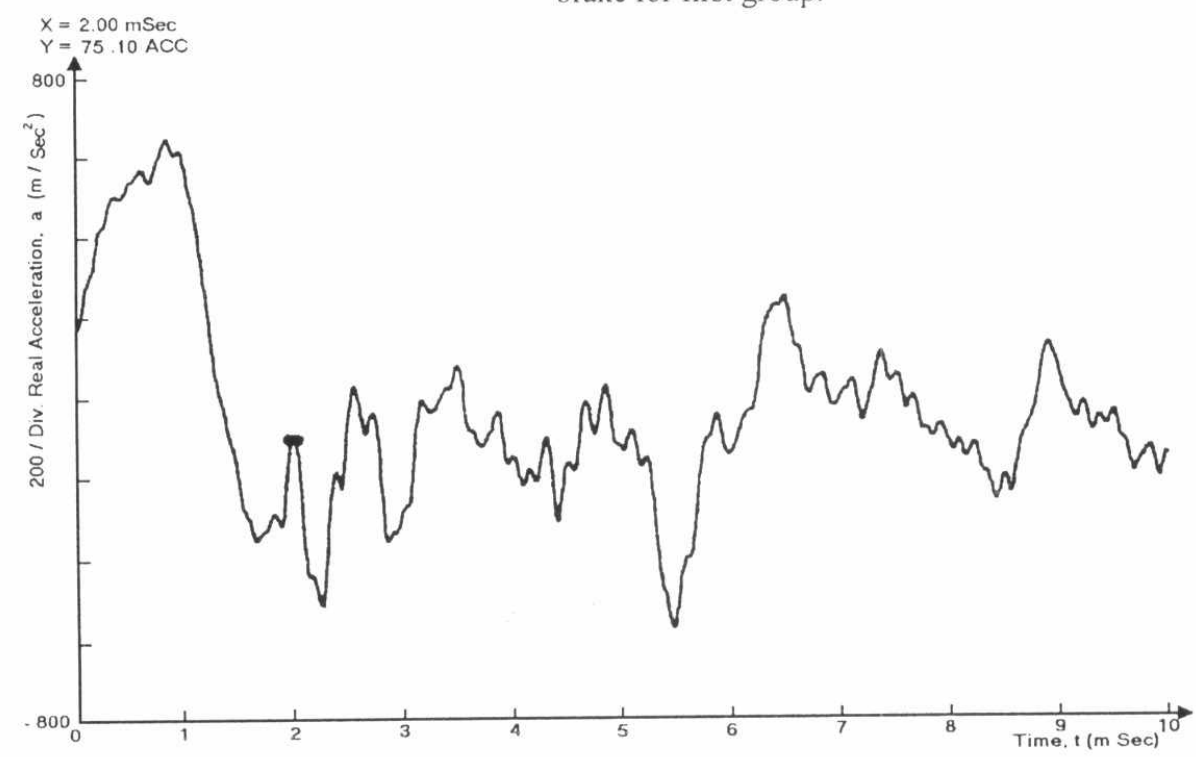

Fig. 12 Measured Vertical Acceleration-time history for automatic rifle with muzzle brake for second group. 


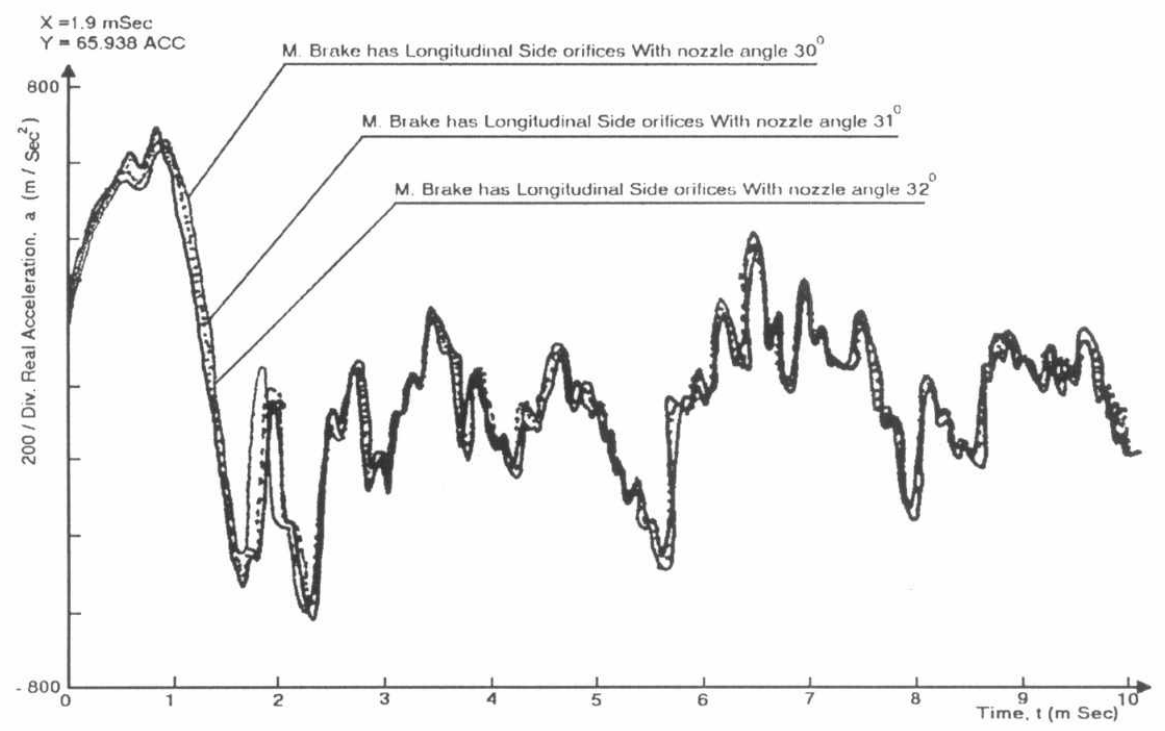

Fig. 13 Measured Vertical Acceleration-time history for automatic rifle with muzzle

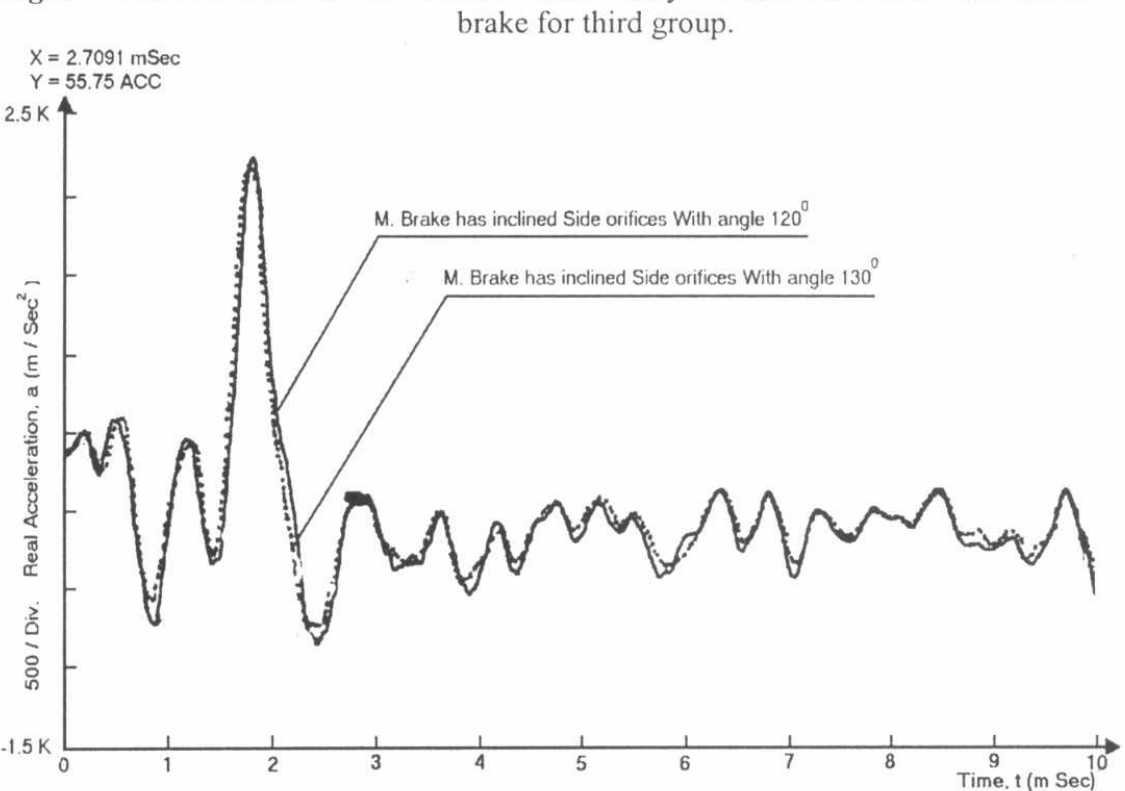

Fig. 14 Measured Horizontal Acceleration- time history for automatic rifle without muzzle brake 


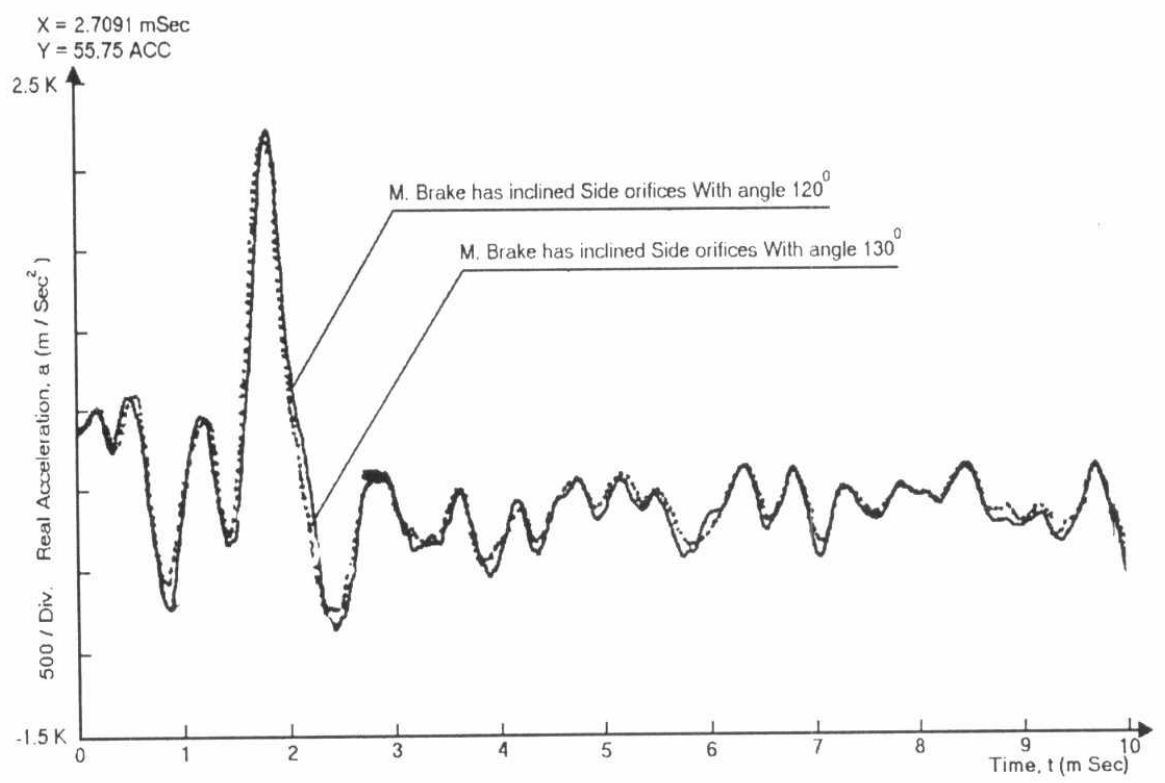

Fig. 15 Measured Horizontal Acceleration-time history for automatic rifle with muzzle brake for first group.

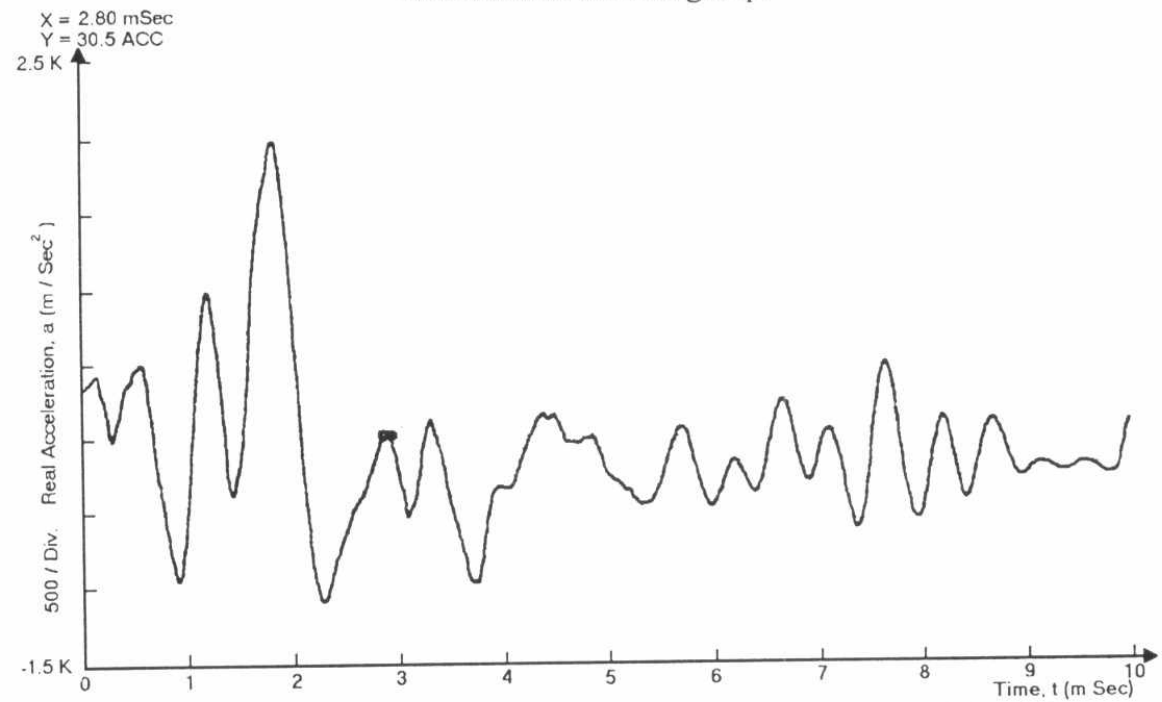

Fig. 16 Measured Horizontal Acceleration-time history for automatic rifle with muzzle brake for second group. 


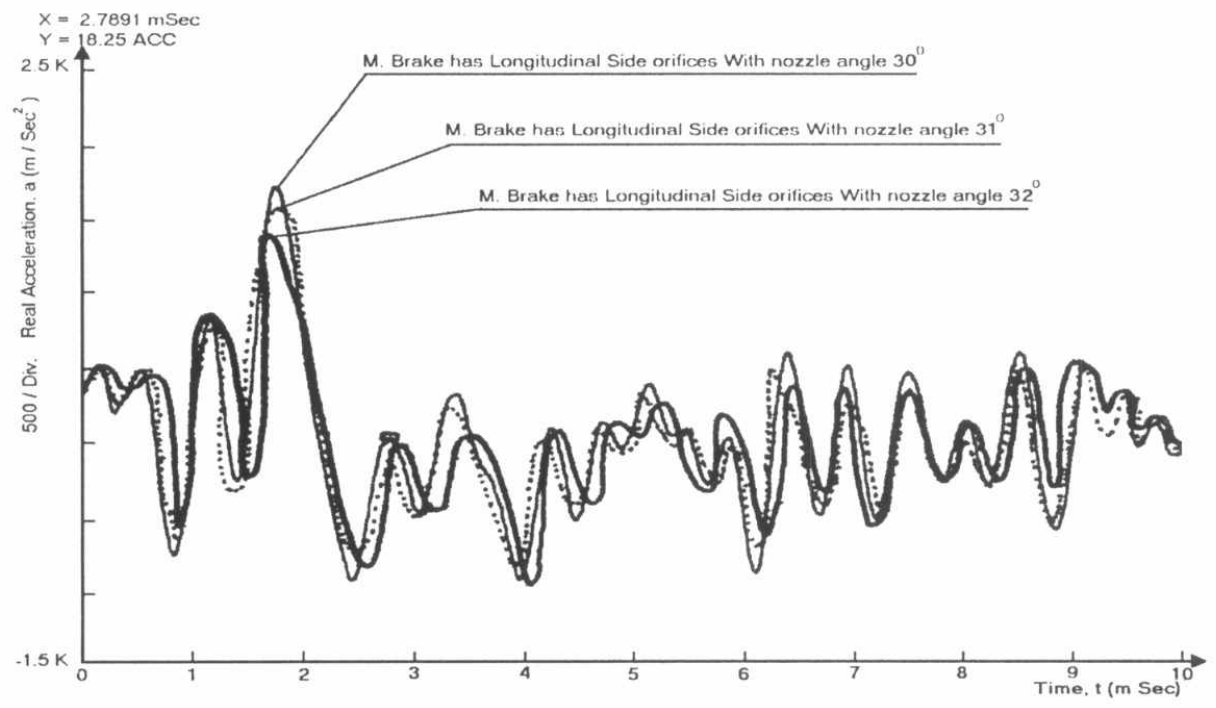

Fig. 17 Measured Horizontal Acceleration-time history for automatic rifle with muzzle brake for third group.

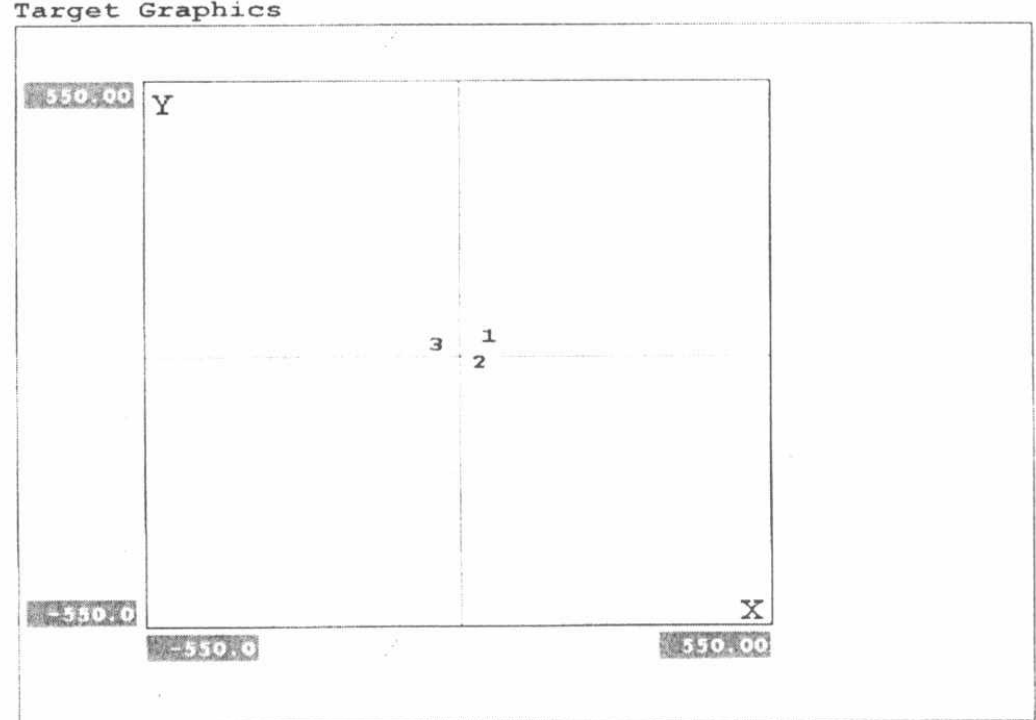

Fig. 18 Target for measuring dispersion and accuracy of firing for automatic rifle with muzzle brake for third group. 


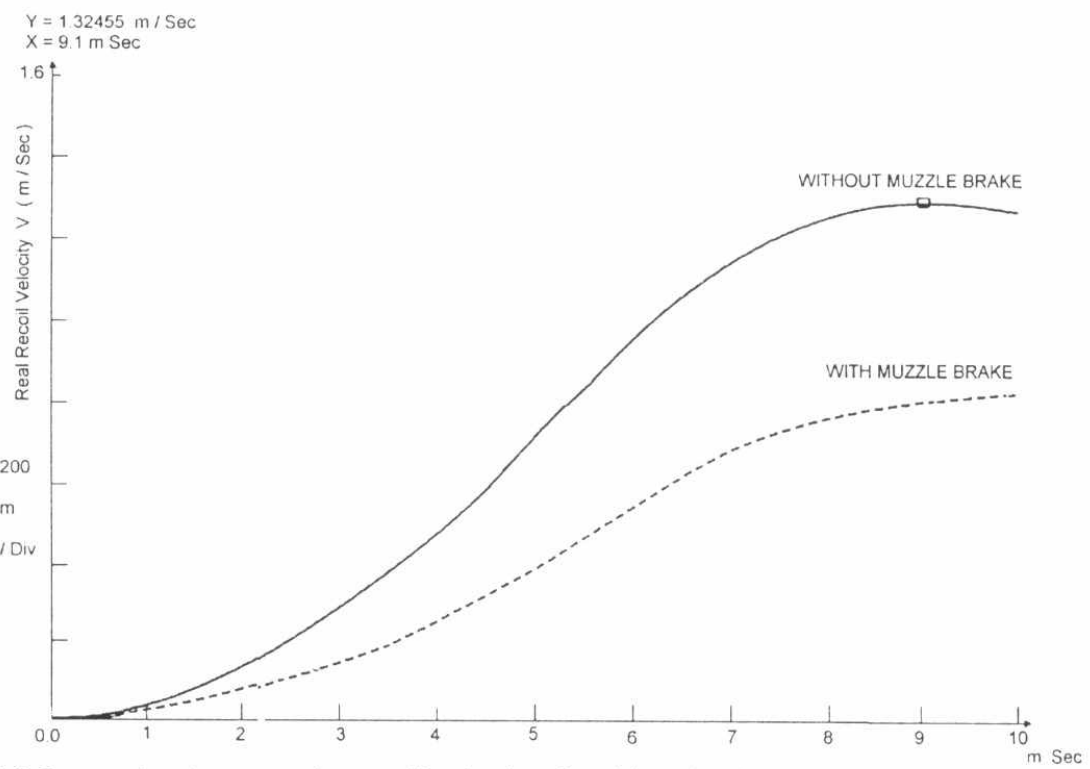

Fig. 19 Comparing between the recoil velocity-time histories for automatic rifle without muzzle brake and with suitable muzzle brake for third group. 